\title{
The influence of level of illumination and size of pattern on the depth perception of the kitten and the puppy'
}

RICHARD D. WALK, PROGRAM IN COGNITIVE AND PERCEPTUAL DEVELOPMENT, GEORGE WASHINGTON UNIVERSITY, Washington, D. C. 20006

Amount of illumination and size of pattern on the deep side of the visual cliff were varied during the development of visual depth perception of the kitten and the puppy. Neither amount of illumination or texture size was found to influence choice behavior. The study also presents normative data on visual cliff responding, the visual placing response, and eyeblink to an approaching object for the puppy.

This study was carried out to determine if level of illumination or size of pattern would influence depth discrimination during perceptual development. Wetzel (1965) found that level of illumination had no influence on adult cats' choice behavior on the visual cliff. Walk \& Gibson (1961) obtained no effect from illumination level on depth perception of the adult rat. Projecting a large pattern from the deep side of the visual cliff, so that the shallow and deep sides have approximately equal pattern density projected to the eye of the animal, has not been found to influence depth discrimination in several species (rat, chick, goat, sheep-Walk \& Gibson, 1961; ducklings-Walk \& Trychin, 1963; human infants-Walk, 1966). Nevertheless, such variables could be an influence during perceptual development. Illumination might be important if the young animal has a tendency to approach or to avoid light, and it would be possible to conclude that depth perception was present when actually the response was based on approach or avoidance of illumination. Texture density might be an important cue during development if the animal is more sensitive to static cues because of its relative immobility as compared to the more active motion of the older animal.

The study will also present some auxillary developmental data on the puppy because of the paucity of perceptual developmental information on this animal. It will supplement the best developmental study of the puppy, that of Fox (1964).

Procedure. All animals were tested from prior to the development of depth perception until it was well established. This was from Days 19 through 28 in the beagle puppies and from Days 14 through 25 in the kittens.

Animals were tested on a large model of the visual cliff (Walk, 1965). A 6 in. wide center board $6 \mathrm{ft}$ long and $3 / 4 \mathrm{in}$. high was used. The shallow side pattern was $1 \mathrm{in}$. black and white commercial cloth checks placed directly under the glass. The deep side pattern was either the same 1 in. checks or 10 in. black and white checks, 20 in. below the glass. Illumination was varied along with size of checks so that the design was a 2 by 2 factorial one for each animal. Illumination on the shallow side was constant: $4.1 \mathrm{ft}-\mathrm{c}$. Illumination for the puppies on the deep side was either $3.5 \mathrm{ft}-\mathrm{c}$ or $5.0 \mathrm{ft}-\mathrm{c}$, one trial on each, four trials a day (the full 2 by 2 design was not instituted for the puppies until Day 22). For the kittens, the illumination level was either $3.5 \mathrm{ft}-\mathrm{c}$ or $5.2 \mathrm{ft}-\mathrm{c}$ on the deep side, eight trials a day or two trials on each of the variables, check size and level of illumination.

The 10 in. checks on the deep side, with the pattern 20 in. below the glass, project an approximately equal texture density to the animal if the animal's eye is about 2-3 in. above the board. Of course, when the 1 in. checks are used on the deep side, projection from it is much finer than is the projection of the texture from the shallow side.

Animals were placed on the 6 in. center board alternately at each end to control for interaction of position (side) preference with pattern or illumination. A trial was terminated if the animal did not get off the center board in 3 $\min$ (puppies), $2 \mathrm{~min}$ (kittens).

For three days (20-22 days of age), the kittens of one litter were subjected to different heights of the center board ( $3 / 4 \mathrm{in}$. or 1-1/2 in.) to determine if tactual cues influenced choice behavior.

The puppies were also tesied for the visual placing response. The animal was brought slowly toward the glass over the deep and the shallow sides of the visual cliff to find out if it extended its paws prior to the nose touching the glass. In addition, the puppies were tested for an eye blink to an approaching object. The hand was brought rapidly toward the animal's face and an eye blink prior to the hand touching the eye was registered. On some trials, a sheet of glass was interposed between the eye of the puppy and the hand of the experimenter.

The Ss were 6 beagle puppies from the same litter, and 11 kittens from two different litters.

\section{Results}

Neither variable, texture density, or level of illumination significantly influenced depth discrimination during perceptual development. The results for each species will be considered separately.

Kittens. The results for level of illumination and texture density are plotted separately in Fig. 1. No significant differences were observed although the curves for texture density seem to be more similar than those for illumination. Overall results for each factor considered separately are also shown in Table 1. The two different litters did not differ significantly.

The three days (Days 20-22 of age) when the height of the center board was manipulated for one litter $(N=6)$ also showed no difference. The $3 / 4$ in. and the $1-1 / 2$ in. height of center board yielded almost identical results: $58 \%$ shallow responses for the $3 / 4 \mathrm{in}$. board and $56 \%$ shallow responses for the $1-1 / 2 \mathrm{in}$. board. Each height of center board also yielded almost an identical number of "no descents": $54 \%$ of all total responses for the $3 / 4$ in. board and $53 \%$ for the $1-1 / 2$ in. board (the "no descents" are ignored in computing the shallow-deep per cents).

Puppies. The puppies were started later on the simultaneous interaction of texture density and illumination. The illumination of the shallow and deep sides was phenomenally equal on the 19th through the 2lst day of age. On the 19th day of age only 1 in. checks were used and on Days 20-21 both 1 in. and 10 in. checks were used. The overall results for these three days were chance: $50 \%$ shallow and 50\% deep descents for the 1 in. checks and 50\% shallow and 50\% deep descents for the 10 in. checks.

Table 1 also shows that illumination and size of checks had no influence on any of the variables considered singly. This table also compares the kittens and the puppies directly on the days when they overlapped in testing (the kittens stopped on Day 25 and the puppies continued on for three more days). The results for kittens and puppies are roughly somparable and one can see no particular trends if one looks at the data as a whole.

Figure 2 shows the per cent of shallow responses for the puppies, all trials together, for Days 19 through 28 . The animals start at a chance level and rapidly approach $100 \%$ choice of the shallow side by Days 27-28. The animals begin above chance choice of the shallow side on Day 22, but this is not a significant difference over Day 21. The data are in essential agreement with those of Fox (1964) who found what he termed "weak and variable" cliff responses between Days 25-27 with strong visual cliff shallow choices from Day 28 on. My data shows positive visual cliff responses a little earlier than his, but he mentioned variations of 1 or 2 days in either direction within or between different litters or breeds. Scott \& Fuller (1965) cite an unpublished study by Mr. Frank Clark of the Jackson Laboratory which found indiscriminate choice of shallow and deep sides of the visual cliff until puppies were about $\mathbf{3 0}$ days of age. Positive visual cliff responses seem to develop sooner than the Clark study would indicate, but without quantitative data this is hard to evaluate.

Visual placing was tested on 24th, 26th, and 33rd day of age. It was absent on the 24th day when the animals made $84 \%$ shallow choices, beginning to come in on the 26th day of age when they went $86 \%$ to the shallow side and strong on the 33rd day; after all animals had been discontinued on the visual cliff. The eye blink to an approaching object was tested occasionally but was present in none

Table 1

Per Cent Shallow Responses for Each Texture and Level of lllumination

\begin{tabular}{|c|c|c|c|c|c|}
\hline Texture & Illumination & Days $14-25$ & $\begin{array}{l}\text { Kittens } \\
\text { Days } 22-25 \\
\end{array}$ & $\begin{array}{cc} & \text { Puppies } \\
\text { Days } & 22-28 \\
\end{array}$ & Days $22-25$ \\
\hline 1 in. checks & Low & 66 & 78 & 84 & 79 \\
\hline 1 in. checks & High & 67 & 93 & 84 & 74 \\
\hline 10 in. checks & Low & 62 & 85 & 85 & 75 \\
\hline 10 in. checks & High & 65 & 83 & 82 & 88 \\
\hline
\end{tabular}

Psychon. Sci., 1968, Vol. 12 (5) 

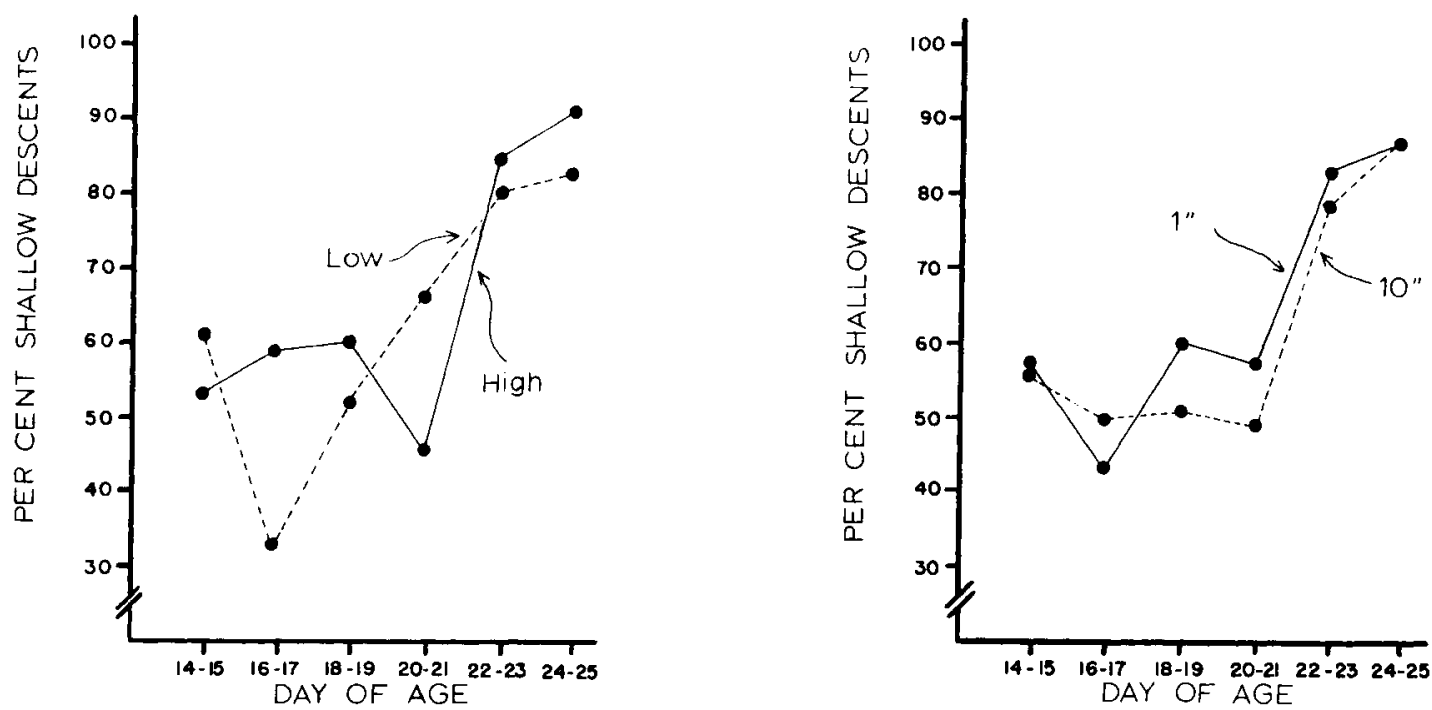

Fig. 1. Per cent shallow descents for the kitten. Illumination level is varied on the left, size of pattern on deep side on the right.

of the animals on the last day tested, the 53rd day.

Discussion. This experiment has shown no influence of pattern density or level of illumination on depth discrimination during perceptual development of the kitten or the puppy. Both variables were within reasonably narrow ranges. Brightness seemed maskedly brighter on the higher illumination trials to the human observer than it did on the low illumination trials. Yet brightness did not influence the behavior of the kittens, animals kept in a dark place by the mother for about the first three weeks of life. Pattern density was also not an important factor. Note that the $\mathrm{l}$ in. checks on the shallow side are very definite checks: stnaller sized checks, such as $1 / 8$ or $1 / 16$ in. checks might have influenced bchavior because of their relation to visual acuity. The 1 in. checks were chosen for this experiment because it was assumed they would be well above the visual acuity level and would permit a better assessment of choice behavior under conditions when equal projected texture density is relatively uninfluenced by the problem of acuity.

Of course, the variables of pattern size and illumination have been found to be unimportant only under the conditions of the present experiment. Wider ranges of the stimuli, for example, might influence behavior: extremely bright lights could induce a photophobic response in almost any species. More pertinent is the interaction of these variables with thresholds for depth perception. The present experiment used a visual depth of 20 in. Booher (1967) constructed a visual cliff to measure the differential depth threshold of small animals. The apparatus permits continuous variation of the deep side toward the shallow side until a point of relative "indifference" is reached. With the deep

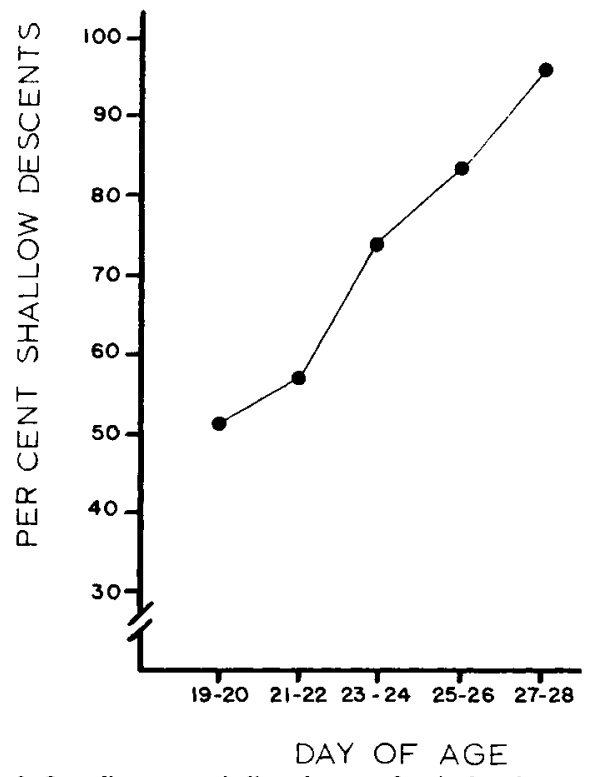

Fig. 2. Overall per cent shallow descents for the beagle puppies. side about $4 \mathrm{in}$. below the glass, rather than at $20 \mathrm{in}$. as in this experiment, one might find some influence during perceptual development of such variables as texture density and illumination. The present experiments show that under conditions of gross depth discrimination neither illumination nor texture density are cues that override the overwhelming importance of motion parallax. It leaves the question open as to whether these variables might have some influence with a more refined analysis of depth perception.

This study has also presented some normative data on the puppy. Visual cliff responding develops rapidly during the fourth week of life (age 22-28 days), in essential agreement with Fox (1964). The visual placing response develops a little later than visual cliff responding and this is in agreement with developmental data secured on visual placing in the kitten. The eye blink to an approaching object was not present at the age of 53 days. Unpublished data from our laboratory secured after these data would indicate that the eye blink to approaching visual objects takes about two months to develop in the kitten, a good comparison since kittens and puppies seem to develop visual behavior at roughly the same rate. All of these data are bound by the conditions under which they were secured. The repeated testing used in this study shows that the animals will soon choose the shallow side invariably despite repeated experience in choosing the deep side at younger ages. However, as Solomon \& Lessac (1968) warn, the repeated testing in developmental research may introduce problems of its own. While I doubt that repeated testing seriously affects the results shown here, I also admit that the effects of "pretesting" on developmental responses of the type investigated here are unknown.

\section{REFERENCES}

BOOHER, H. R. Differential visual depth perception threshold in the hooded rat. Unpublished M. A. thesis, George Washington Univ., 1967.

FOX, M. W. The ontogeny of behaviour and neurologic responses in the dog. Anim. Behav., 1964,12,301-310.

SCOTT, J. P., \& FULLER, J. L. Genetics and the social behavior of the dog. Chicago: Univ. of Chicago Press, 1965.

SOLOMON, R. L., \& LESSAC, M. S. A control group design for experimental studies of developmental processes. Psychol. Bull., 1968, in press.

WALK, R. D. The development of depth perception in animals and human infants. Child Develpm. Monogr. 1966, 31, 82-108, (Whole No. 107).

WALK, R. D. The study of visual depth and distance perception in animals. In D. S. Lehrman, R. A. Hinde, and E. Shaw (Eds.), Advances in the study of behavior. Vol. 1. New York: Academic Press, 1965. Pp. 99-154.

WALK, R. D., \& GIBSON, E. J. A comparative and analytical study of visual depth perception. Psychol. Monogr., 1961, 75, No. 15, (Whole No. 519).

WALK, R.D., \& TRYCHIN, S., J. Unpublished research, 1963.

WETZEL, A. B. Visual cortical lesions in the cat: a study of depth and pattern discrimination. Unpublished doctoral dissertation, Ohio State Univ., 1965.

\section{NOTE}

1. Supported, in part, by NSF grant GB-4351 and by a NIH Biomedical Sciences Support Grant to George Washington University. I thank my children, Joan, Betsy and David, for their help in experimenting with the beagle puppies, and my wife, Lois, for her thoughtful patience during the breeding, birth, and aftercare of a litter of 6 puppies that did damage to our house and pocketbook unrecompensed by any grant or grants, tax deductions, etc., as they turned our house into a shambles and a circus for two months. I also thank Elizabeth $\mathrm{K}$. Bond for her assistance in experimentation with the kittens.

Psychon. Sci., 1968, Vol. 12 (5) 